\title{
Symposium review: Recent advances in dairy food safety research: An overview of the National Dairy Council Listeria Consortium, industry identification, and funding of research gaps*
}

\author{
T. A. Stubbs† ${ }^{\circ}$ and C. D. Galert $(1)$
}

National Dairy Council, 10255 West Higgins Road, Suite 900, Rosemont, IL 60018

\section{ABSTRACT}

Consumers should have confidence that dairy foods are safe to eat. The Food Safety Committee of the Innovation Center for US Dairy (IC), created in 2010 to help processors collectively improve practices and reduce risks in dairy foods, is an industry-wide food safety collaboration that aims to protect the public through its mission to "Strengthen manufacturing practices in all dairy processing facilities and advance science-based tools to diminish food safety risks that could compromise the reputation of the U.S. dairy industry." The IC Listeria Research Consortium, a subset of the IC Food Safety Committee, funds research directed at creating new tools and practices to control Listeria in finished products and in manufacturing plants. This synopsis summarizes a presentation on the work conducted by the IC Food Safety Committee and research funded by the IC Listeria Research Consortium that was part of a symposium highlighting recent scientific findings and potential practical approaches to better control Listeria using science-based tools.

Key words: dairy food safety, National Dairy Council, Listeria

\section{INTRODUCTION}

The Innovation Center for US Dairy (IC; Rosemont, IL) is a leadership organization that leverages the collective strengths of the dairy community to ensure an economically viable and socially responsible US dairy community from farm to table. Initiated in 2008 by America's dairy farmers, the IC brings together dairy farmers, cooperatives, processors, and other organiza-

Received July 26, 2019

Accepted August 28, 2019.

*Presented as part of the Dairy Foods Symposium: Recent Advances in Dairy Food Safety Research at the ADSA Annual Meeting, Cincinnati, Ohio, June 2019.

†Corresponding authors: Tim.Stubbs@Dairy.org and Chad.Galer@ Dairy.org tions to work together pre-competitively. The board of directors includes chief executive officers and chairs of dairy companies representing approximately $60 \%$ of the US milk supply, and of dairy organizations, including the International Dairy Foods Association (www .idfa.org), Milk Processors Education Program (www .milkpep.org), National Milk Producers Federation (www.nmpf.org), and the US Dairy Export Council (www.usdec.org). Through the IC, the dairy community identifies and builds alignment on best-in-class practices and develops programs that demonstrate its collective commitment to provide the world responsibly produced dairy foods that nourish people, strengthen communities, and foster a sustainable future.

The Food Safety Committee of the IC helps protect consumers and maintains trust in dairy by providing resources and training for dairy manufacturing. The activities of the IC Food Safety Committee focus on sharing best practices, research, training, and creation of tools and guidance documents. Since its inception, the IC Food Safety Committee has focused on broadening the adoption of current tools and best practices. In 2015, the IC Food Safety Committee initiated an industry-funded Listeria Research Consortium to advance science with the ultimate goal of protecting public health.

Research is just one of the ways the committee works to improve the control of pathogens in dairy processing. Additional action platforms include pathogen control across the dairy industry through best-practice sharing via the Dairy Plant Food Safety workshops. Specific efforts are also tailored to artisan and farmstead cheese and dairy producers through tools, resource websites, online classes, and hands-on education because of their unique needs. The complexity of the food industry supply chain requires food manufacturers to manage supplier and supply chain risks. To help address these needs, the IC provides training through the Dairy Supplier Management Food Safety workshops, which include free tools to help processors build a robust supplier program. The IC Food Safety Committee also convenes industry experts to write guidance documents 
for traceability and pathogen controls, which are widely used to advance best practices by the dairy industry. The balance of this synopsis focuses on the Listeria Research Consortium, but more information including access to tools and training can be found at www .usdairy.com/foodsafety.

\section{RESEARCH FOCUS OF THE LISTERIA CONSORTIUM}

The purpose of creating the Listeria Research Consortium was to expand dairy's toolkit by leveraging both industry and academic experts to identify gaps in knowledge and charter pre-competitive research. The Listeria Research Consortium, in partnership with National Dairy Council, has issued several requests for research proposals directed at creating new tools and practices to control Listeria in finished products and in manufacturing environments. The 3 focus areas for research currently include control of Listeria, Listeria fundamentals, and Listeria mitigation in high-risk cheeses.

\section{Research Area 1: Control of Listeria}

The request for proposals in research area 1 focuses on identifying new tools to control Listeria in dairy. Projects are designed to identify solutions that are novel to dairy and sometimes include combination approaches to mitigating Listeria. These solutions must be applicable to either or both dairy products and manufacturing plant environments, with minimal impact on taste and functionality of the final dairy product. Ideal solutions are effective in a broad range of products, manufacturing environments, and equipment. Funded research has included approaches that may include but are not limited to protective cultures, antimicrobial metabolites, fermentates, bacteriophages, competitive exclusion, and antimicrobial ingredients; Listeria mitigating processing or packaging steps; and technologies for practical, cost-effective Listeria mitigation in dairy plant environments.

\section{Research Area 2: Listeria Fundamentals}

The request for proposals in research area 2 focuses on improved understanding of the biochemical pathways of Listeria. This research is needed to develop the next level of control mechanisms for use in dairy foods and processing environments. The research conducted in this area advances our understanding of growth and virulence factors to exploit Listeria's vulnerabilities. Funded research may include but is not limited to mechanisms of Listeria survival in dairy foods; mecha- nisms of Listeria survival in processing environments, including biofilm formation; and control of gene expression and virulence

\section{Research Area 3: Listeria Mitigation in High Risk Cheeses}

The request for proposals in research area 3 focuses on reduction of Listeria risk in cheeses that are more susceptible to Listeria growth due to composition (neutral $\mathrm{pH}>5.6$, high moisture $>50 \%$ ) or manufacturing procedures (no cultures, surface-ripened, washed rind, use of smear, product exposure to environment, and handling before packaging). Among cheese types that may exhibit these characteristics are Queso Fresco, Panela, Camembert, and Brie. The research that is conducted in this area offers solutions with minimal effects on product flavor and functionality. Funded research may include but is not limited to identification and application of protective ingredients; identification and application of protective cultures or bacteriocin producing organisms; treatments before packaging to improve the safety of fresh or surface-ripened cheeses; and in-package and after-packaging treatments.

\section{Funded Research Projects}

To date, 11 research projects have been funded by the IC Listeria Research Consortium (Table 1). From these projects, several articles have been published (Brown et al., 2018; Kozak et al., 2018a,b; Wan et al., 2019) or are pending publication in the peer-reviewed literature. This work has identified several promising approaches that reduced Listeria in proof-of-principle studies and has led to the funding of extensions or additional projects that will help drive commercialization and adoption. Such approaches include hydrogen peroxide dips, atmospheric cold plasma, and effect of acid type to control microbial growth in cheese.

\section{Beyond Research: The Whole Is Greater than the Sum of its Parts}

The collaborative approach of the Listeria Research Consortium allows members to optimize research by using their combined expertise without crossing competitive boundaries. Because consumer safety and trust in dairy foods can be hurt by one compromised manufacturing environment, it is advantageous to all in the industry to ensure best practices. The Listeria Consortium consists of subject matter experts from many companies with various backgrounds who volunteer their time and invest their expertise on behalf of the industry as a whole. The result has been collaboration 
Table 1. Research projects funded by the Innovation Center for US Dairy (IC) Listeria Research Consortium ${ }^{1}$

\begin{tabular}{|c|c|c|}
\hline $\begin{array}{l}\text { Principal } \\
\text { investigator }\end{array}$ & Institution & Title of project \\
\hline D. D'Amico & University of Connecticut & $\begin{array}{l}\text { Utilization of GRAS compounds as antimicrobial dip and coating treatments for } \\
\text { controlling Listeria monocytogenes on high moisture cheese (Brown et al., 2018; Kozak et } \\
\text { al., 2018a,b) }\end{array}$ \\
\hline M. Wiedmann & Cornell University & $\begin{array}{l}\text { Understanding regulation of Listeria monocytogenes cell envelope composition to facilitate } \\
\text { development and discovery of improved control strategies }\end{array}$ \\
\hline K. Glass & University of Wisconsin & $\begin{array}{l}\text { Combinations of acid type, pH, and commercial clean-label antimicrobial ingredients on } \\
\text { the growth of Listeria monocytogenes in high-moisture cheese }\end{array}$ \\
\hline K. Keener & Iowa State University & $\begin{array}{l}\text { Controlling Listeria monocytogenes in high risk cheeses by treatment with high voltage } \\
\text { atmospheric cold plasma (HVACP) (Wan et al., 2019) }\end{array}$ \\
\hline M. Brashears & Texas Tech University & $\begin{array}{l}\text { Inhibition of Listeria monocytogenes on cheese using lactic acid bacteria as a biocontrol } \\
\text { system intervention }\end{array}$ \\
\hline D. D'Amico & University of Connecticut & $\begin{array}{l}\text { Determining the efficacy of novel glycolipid to control Listeria monocytogenes } \\
\text { contamination throughout the production and storage of high risk cheese }\end{array}$ \\
\hline T. Huynh & University of Wisconsin & $\begin{array}{l}\text { A novel GRAS natural antimicrobial to control Listeria in the dairy processing } \\
\text { environment }\end{array}$ \\
\hline
\end{tabular}

${ }^{1}$ Research funded by the IC Listeria Research Consortium with contributions by 11 dairy processors and co-ops, the Midwest Dairy Association (St. Paul, MN), and National Dairy Council (Rosemont, IL).

that allows participants to expand their knowledge and bring it back to their own companies.

\section{CONCLUSIONS}

The IC Food Safety Committee is committed to widely disseminating best practices and providing science-based tools that help companies ensure the food they produce is safe. We believe that the research funded by the Listeria Research Consortium that was presented at the ADSA Dairy Foods Symposium: Recent Advances in Dairy Food Safety Research will drive awareness of scientific advances and new tools that can help the industry improve the control of pathogens.

\section{ACKNOWLEDGMENTS}

The Innovation Center of U.S. Dairy Listeria Research Consortium is funded by Darigold, Foremost Farms USA, Glanbia Foods, Great Lakes Cheese, Hilmar Cheese and Ingredients, Land O'Lakes, Leprino Foods, Prairie Farms, Saputo Cheese, Sargento Foods, Wells Enterprises, the Midwest Dairy Association, and the National Dairy Council.

\section{REFERENCES}

Brown, S. R. B., S. M. Kozak, and D. J. D'Amico. 2018. Applications of edible coatings formulated with antimicrobials inhibit Listeria monocytogenes growth on Queso Fresco. Front. Sustain. Food Sys. https://doi.org/10.3389/fsufs.2018.00001.

Kozak, S. M., Y. Bobak, and D. J. D'Amico. 2018a. Efficacy of antimicrobials applied individually and in combination for controlling Listeria monocytogenes as surface contaminants on Queso Fresco. J. Food Prot. 81:46-53. https://doi.org/10.4315/0362-028X.JFP $-17-279$.

Kozak, S. M., S. R. B. Brown, Y. Bobak, and D. J. D'Amico. 2018b. Control of Listeria monocytogenes in whole milk using antimicrobials applied individually and in combination. J. Dairy Sci. 101:1889-1900. https://doi.org/10.3168/jds.2017-13648.

Wan, Z., S. K. Pankaj, C. Mosher, and K. M. Keener. 2019. Effect of high voltage atmospheric cold plasma on inactivation of Listeria innocua on Queso Fresco cheese, cheese model and tryptic soy agar. Lebensm. Wiss. Technol. 102:268-275. https://doi.org/10 .1016/j.lwt.2018.11.096.

\section{ORCIDS}

T. A. Stubbs (ํ) https://orcid.org/0000-0003-2071-4388

C. D. Galer (1) https://orcid.org/0000-0001-8048-2545 